\title{
Racial group, socioeconomic status, and the development of persistent proteinuria in systemic lupus erythematosus
}

\author{
N D Hopkinson, C Jenkinson, K R Muir, M Doherty, R J Powell
}

\begin{abstract}
Objectives-Systemic lupus erythematosus (SLE) patients of Afro-Caribbean and Asian origin living in the United Kingdom have a more severe spectrum of disease compared with the white population but whether this is attributable to genetic host factors or environmental factors is unclear. This study examines time from first symptom to onset of persistent proteinuria, as a marker of renal disease, to assess which factors are important.

Methods-The 189 patients studied were ascertained using multiple methods and included 161 white, 22 Afro-Caribbean and six Asian patients. Time of first observation of persistent proteinuria ( $\geqslant 0.5 \mathrm{~g} /$ day) was taken as onset of renal SLE. Initial univariate analysis to determine which factors are associated with onset of renal disease was followed by using a Cox's proportional hazards regression model enabling analysis of several prognostic factors at the same time. Variables included three measures of socioeconomic status, ethnic group and the presence or absence of different autoantibodies.

Results-There was no effect from any socioeconomic variable. Using forwards stepwise selection, the following had independent effects $(p<0.05)$ on the development of renal SLE: Afro-Caribbean race (hazard rate ratio $4.4(1.9-10.2)$, compared with white population); and the presence of IgG anti-cardiolipin antibodies (hazard rate ratio $2.6(1.2-5.7)$ ) .

Conclusion-Differing socioeconomic factors do not explain the increased frequency of lupus nephritis in AfroCaribbean patients with SLE, but rather there are important genetic or other host differences. The independent effect of IgG anti-cardiolipin antibodies warrants further investigation.
\end{abstract}

(Ann Rheum Dis 2000;59:116-119)

In the United Kingdom systemic lupus erythematosus (SLE) is more common in both Afro-Caribbeans and Asians than in the white population. ${ }^{1-3}$ There is also evidence from the UK and USA that non-white people have a more severe disease spectrum than the white population, including renal and cerebral manifestations. ${ }^{25}$ Both social class, ${ }^{6}$ noncompliance and type of medical insurance ${ }^{7}$ may explain this increased risk, but more recent data suggest that genetic factors are important in predicting an increased incidence of lupus nephritis in African Americans. ${ }^{8}$ Furthermore, Reveille et al, suggest that both genetic and socioeconomic factors determine SLE presentation. $^{9}$

We have therefore further investigated the role of environmental factors and autoantibodies in the development of renal SLE using Cox ${ }^{10}$ survival analysis.

\section{Methods}

The study was approved by the local ethics committee.

\section{PATIENTS}

The 201 SLE patients all fulfilled four or more of the revised ARA criteria ${ }^{11}$ and were ascertained at the time of a concurrent epidemiological study using six principal methods ${ }^{12}$ :

1 Notification by physicians working at the two main Nottingham hospitals.

2 A register of patients with connective tissue disease collated in the immunology department.

3 Screening of immunology investigation request cards, with follow up of patients with positive anti-nuclear antibodies (ANA, titre $>1: 25$ ) or antibodies to dsDNA and/or with clinical details on the card relevant to a diagnosis of SLE.

4 The Nottingham renal unit computer.

5 The inpatient medical records computer.

6 Screening of acute psychiatric and psychogeriatric inpatient admissions.

There was marked overlap of retrieval of cases and so ascertainment was high from the geographically defined area of Greater Nottingham, but the cohort in this study also included those patients under regular follow up but not residing in Greater Nottingham.

\section{DATA}

From a detailed interview with all patients, data were obtained on: date of first definite symptom of SLE; date of onset of renal disease; follow up period (from date of first symptom and diagnosis to onset of renal disease or patient interview, in months); smoking history before and after the first SLE symptom; alcohol consumption before and after the first SLE symptom; socioeconomic status; ethnic group - that is, white, Asian, or AfroCaribbean; sex; previous SLE treatment (use of azathioprine, cyclophosphamide, prednisolone and hydroxychloroquine); presence or absence, at any time, of: antibodies to extractable
Accepted for publication 28 October 1999 
Table 1 Race and demographic details of patients with and without renal disease

\begin{tabular}{|c|c|c|c|c|}
\hline Variable & $\begin{array}{l}\text { Renal disease } \\
(n=28)\end{array}$ & $(\%)$ & $\begin{array}{l}\text { No renal disease } \\
(n=161)\end{array}$ & $(\%)$ \\
\hline \multicolumn{5}{|l|}{ Race } \\
\hline White & 19 & 68 & 142 & 88 \\
\hline Asian & 1 & 4 & 5 & 3 \\
\hline \multirow{2}{*}{\multicolumn{5}{|c|}{ Social class }} \\
\hline & & & & \\
\hline Professional & 1 & 4 & 9 & 6 \\
\hline Intermediate & 10 & 36 & 36 & 22 \\
\hline Skilled & 13 & 46 & 75 & 47 \\
\hline Partly skilled & 3 & 11 & 32 & 20 \\
\hline Unskilled & 1 & 4 & 4 & 2 \\
\hline Not classifiable & 0 & 0 & 5 & 3 \\
\hline \multicolumn{5}{|l|}{ Disadvantage } \\
\hline Below average & 12 & 43 & 72 & 45 \\
\hline Moderate & 2 & 7 & 10 & 6 \\
\hline Serious & 3 & 11 & 17 & 11 \\
\hline Extreme & 2 & 7 & 17 & 11 \\
\hline Not classifiable & 9 & 32 & 45 & 28 \\
\hline \multicolumn{5}{|l|}{ Residence status } \\
\hline Private landlord & 0 & 0 & 6 & 4 \\
\hline Council tenant & 3 & 11 & 24 & 15 \\
\hline Owner/occupier & 24 & 86 & 125 & 78 \\
\hline Unclassifiable & 1 & 4 & 6 & 4 \\
\hline
\end{tabular}

nuclear antigens (ENA), Ro, La, Sm and RNP; anti-dsDNA antibodies; IgG and IgM anticardiolipin antibodies (ACA), and lupus anticoagulant (LA).

The date of onset of renal disease was defined as the presence of persistent proteinuria $(\geqslant 0.5 \mathrm{~g} / 24 \mathrm{~h}$ ) detected by +++ urine dipstick reaction for albumin and confirmed on 24 hour urine protein quantification. Other factors such as microscopic haematuria or sterile pyuria were not routinely measured. Patients with persistent proteinuria who had a known history of hypertension or diabetes were not included in the study.

To clarify date of onset of proteinuria in relation to time of first symptom, only patients with an interval from first symptom to onset of persistent proteinuria of over four months were used in the analysis.

SOCIOECONOMIC STATUS

Three measures were used:

1 The occupation of the economically active person in the household of the patient was graded into five groups ${ }^{13}$ : professional or managerial; intermediate; skilled manual or non-manual; semi-skilled manual; or unskilled manual. Certain people such as students could not be graded into these recognised groupings, as they have different social circumstances, and therefore were included as unclassifiable.

2 Based on area of residence, an index of multiple disadvantage is available for Nottinghamshire. ${ }^{14}$ This is calculated from indicators of low income, unemployment, lack of skills, poor housing, poor health and family/education problems. There are four levels of disadvantage, below average, moderate, serious and extreme.

Table 2 Serological data of the 189 SLE patients with and without renal disease

\begin{tabular}{lllll}
\hline Variable & $\begin{array}{l}\text { Renal disease } \\
(n=28)\end{array}$ & $(\%)$ & $\begin{array}{l}\text { No renal disease } \\
(n=161)\end{array}$ & (\%) \\
\hline Anti-dsDNA -ve & 8 & 29 & 84 & 52 \\
Anti-dsDNA +ve & 20 & 71 & 77 & 48 \\
Anti-La -ve & 28 & 100 & 140 & 87 \\
Anti-La +ve & 0 & 0 & 21 & 13 \\
\hline
\end{tabular}

3 Residence status for each patient was assessed (that is, whether or not they owned their home, were a council tenant or rented accommodation from a landlord).

STATISTICS

All data were analysed using Epidemiological Graphics, Estimation and Testing (EGRET) statistical software. ${ }^{15}$ Analysis of data was by survival time analysis using onset of renal disease as the end point of interest. Variables suggesting a statistically significant $(p \leqslant 0.1)$ difference in rate of onset of renal disease over the study period were examined using the Cox's proportional hazards regression model and both forward selection and backwards elimination methods were used to select those variables significantly associated $(p \leqslant 0.05)$ with the outcome. ${ }^{16}$

When onset of renal disease occurred as an early SLE manifestation it was often unclear if proteinuria was present at the time of first definite SLE symptom. Therefore patients with a follow up time between first symptom and onset of renal disease or patient interview of less than four months were not included in the analysis. To minimise problems with left censorship bias (see later discussion) available data on the four identified SLE patients who had died in the three years before the study period was also included in the analysis.

\section{Results}

Of the original 201 SLE patients, 189 had a follow up interval of over four months, from time of first symptom to renal disease or patient interview, and were therefore used in the analysis. The group comprised 177 women and 12 men; there were no patients of mixed origin, with 161 white patients, six Asian patients, and 22 Afro-Caribbean patients. Although it is difficult to draw conclusions from the small number of Asian patients in the study, they were included as this racial group does have an increased frequency of renal disease. ${ }^{2}$ The median age at diagnosis was 39 years (range 13-83) with a median follow up interval (from time of first symptom to renal disease or interview) of 96 months (range 5-560).

Tables 1 and 2 show distribution of various factors with regard to presence of renal disease.

Initial univariate analysis (table 3) showed that alcohol consumption before SLE diagnosis, anti-La antibodies, increasing age at diagnosis of SLE, and previous treatment with antimalarial drugs were significantly associated with a decrease in risk of renal disease; while Afro-Caribbean race, anti-dsDNA antibodies, and IgG anti-cardiolipin antibodies were associated with an increase in the risk of renal disease. There was no effect from any socioeconomic variable.

These variables were then entered into both forwards and backwards stepwise multivariate analysis. The final model using forwards stepwise selection (table 4) showed that Afro-Caribbean race and IgG anti-cardiolipin antibodies had significant independent associations with the development of renal disease. 
Table 3 Variables shown to be significantly associated with onset of renal lupus on initial univariate analysis

\begin{tabular}{llll}
\hline Variable & p Value & $\begin{array}{l}\text { Hazard } \\
\text { rate ratio }\end{array}$ & $\begin{array}{l}95 \% \\
\text { Confidence } \\
\text { intervals }\end{array}$ \\
\hline Alcohol consumption & 0.04 & 0.4 & $0.16,1.00$ \\
Anti-dsDNA antibodies & 0.05 & 2.2 & $0.97,5.00$ \\
Anti-La antibodies & 0.05 & $\star$ & $\star$ \\
Afro-Caribbean race & $<0.01$ & 3.9 & $1.69,8.91$ \\
Age at SLE diagnosis & 0.04 & 0.4 & $0.19,0.99$ \\
IgG anti-cardiolipin antibodies & 0.03 & 2.3 & $1.08,4.94$ \\
Previous treatment with antimalarials & 0.03 & 0.5 & $0.21,0.94$ \\
\hline
\end{tabular}

^No patients with anti-La antibodies and renal disease.

Table 4 Estimates of relative rate of onset of renal disease (lupus) for significant independent prognostic factors according to Cox proportional hazards model (forward selection)

\begin{tabular}{llllll}
\hline Number & \multirow{2}{*}{$\chi^{2}$ Model } & $p$ Value & $\begin{array}{l}\text { Variables } \\
\text { included }\end{array}$ & \multicolumn{2}{l}{ Hazard rate ratio $(95 \%$ CI) } \\
\hline 1 & 8.24 & $<0.001$ & Racial group & Caucasian & 1.0 \\
& & & Asian & $1.5(0.2,11.2)$ \\
& & & Afro-Caribbean & $3.9(1.7,8.9)$ \\
& \multirow{2}{*}{13.8} & 0.003 & Racial group & Caucasian & 1.0 \\
& & 0.01 & APAG & Asian & $1.3(0.2,10.0)$ \\
& & & Afro-Caribbean & $4.4(1.9,10.2)$ \\
& & & APAG & $2.6(1.2,5.7)$ \\
\hline
\end{tabular}

Using backwards stepwise selection a different model was seen, with age at diagnosis $(\mathrm{p}=0.02$, $\mathrm{HRR}=0.37(0.2-0.9)$ and previous treatment with antimalarials $(p=0.01, H R R=0.37(0.2$ $0.8)$ ) also having significant effects. AfroCaribbean race, however, still had the greatest risk $(\mathrm{p}=0.003, \mathrm{HRR}=3.6(1.6-8.1))$.

Inclusion of data on the four identified patients who had died before this study did not make any significant difference to the results.

\section{Discussion}

The overall prevalence of renal disease in this cohort is approximately $15 \%$, somewhat lower than other studies, ${ }^{17}{ }^{18}$ but this is probably attributable to the study patients being from a predominately geographical cohort rather than from a tertiary referral centre.

Socioeconomic status has been assessed in three ways including a specific disadvantage score developed for Nottinghamshire. The latter is dependent on the place of residence rather than addressing individual patients, but has the advantage over a classification system based solely on occupation in that variables such as education are taken into account. The greatest risk factor for the development of renal SLE was Afro-Caribbean race and no effect of socioeconomic status was seen. Therefore genetic factors may explain this increased risk, although individual environments or cultural effects cannot be ruled out.

This study is therefore in agreement with more recent work by Salmon et al, ${ }^{8}$ who found a strong genetic association in African Americans between a polymorphic allele of FeGRIIa and lupus nephritis. Trend analysis of the genotype distribution showed that as Fc gamma RIIA-H131 decreased, the likelihood for lupus nephritis increased. It has been suggested that this could represent a disease severity gene influencing development of lupus nephritis in African Americans, but having no role in the development of SLE itself. ${ }^{19}$
These results are in discordance with some previous studies that have emphasised the importance of socioeconomic status ${ }^{62021}$ with regard to the higher incidence of SLE seen in Afro-Caribbeans. However, Petri et al also found that the increased morbidity (renal disease and hypertension) in American blacks with SLE was not explained by socioeconomic status but, rather, that non-compliance with treatment and type of medical insurance were likely to be important. ${ }^{7}$

In the study by D'Cruz et $a l^{22}$ the association of Afro-Caribbean origin and nephritis was explained by the increased prevalence of RNP and $\mathrm{Sm}$ in Afro-Caribbeans. A further interesting finding in our study was that positive IgG anti-cardiolipin antibodies were an independent risk factor in the development of renal SLE. McAlindon et al have previously reported that fetal loss after the onset of SLE was also a risk factor for renal SLE and suggest that it is a further marker of more severe disease ${ }^{6}$ However, the increased risk may be accounted for by anti-cardiolipin antibodies that were not specifically examined. In this study, the presence of IgG anti-cardiolipin antibodies, rather than anti-dsDNA antibodies were the stronger risk factor in the development of renal SLE, even though in this series of patients the presence of positive anti-cardiolipin antibodies correlates strongly with the presence of antibodies against dsDNA $^{23}$ and anti-dsDNA antibodies have been implicated in the pathogenesis of renal SLE. ${ }^{24}$

Methodological problems with studies of this type have recently been highlighted, ${ }^{25}$ in particular that of left censorship bias. In this study maximum care was taken, using a number of ascertainment methods, to ensure that even patients with SLE who may have defaulted from clinic were included. Furthermore, the patients known to have died before the study were also included in the analysis.

In summary, this study suggests that differing socioeconomic factors do not explain the increased frequency of lupus nephritis in AfroCaribbean patients with SLE, but supports recent evidence that there are particular risk genes that predict lupus nephritis in African Americans. Similar genetic analysis of AfroCaribbeans in the United Kingdom is now indicated.

The authors are grateful to Sue Benjamin for preparation of this manuscript.

1 Hopkinson N, Doherty M, Powell R. Race-specific incidence and prevalence rates for systemic lupus erythematosus in Nottingham, UK. Br J Rheumatol 1994;33 (suppl1):46

2 Samanta A, Feehally J, Roy S, Nicol F, Sheldon P,Walls J. High prevalence of systemic disease and mortality in Asian subjects with systemic lupus erythematosus. Ann Rheum Dis 1991;50: 490-2

3 Johnson A, Gordon C, Bacon P, Palmer R. The incidence and prevalence of SLE amongst different ethnic groups in Birmingham, UK. Br J Rheumatol 1993;32 (suppl 2):30.

4 Kaslow R. High rate of death caused by systemic lupus erythematosus among US residents of Asian descent. Arthritis Rheum 1982;25:414-18.

5 Ginzler EM, Diamond HS, Weiner M, Schlesinger M, Fries $\mathrm{JF}$, Wasner $\mathrm{G}$, et al. A multicentre study of outcome in systemic lupus erythematosus I. Entry variables as predictors temic lupus erythematosus I. Entry variables as pre
of prognosis. Arthritis Rheum 1982;25:601-11.

6 McAlindon T, Giannotta L, Taub N, D'Cruz D, Hughes G. Environmental factors predicting nephritis in systemic lupus erythematosus. Ann Rheum Dis 1993;52:720-4. 
7 Petri M, Perez-Gutthann S, Longenecker J, Hochberg M. Morbidity of systemic lupus erythematosus: role of race and socio-economic status. Am J

8 Salmon JE, Millard S, Schachter LA, Arnett FC, Ginzler EM, Gourley MF, et al. Fc gamma RIIA alleles are heritable risk factors for lupus nephritis in African Americans. J Clin Invest 1996;97:1348-54

9 Reveille JD, Moulds JM, Ahn C, Friedman AW, Baethge B, Roseman J, et al. Systemic lupus erythematosus in three groups. Arthritis Rheum 1998;41:1161-72

10 Cox D. Regression models and life tables. J R Stat Soc [B] 1972;34:187-220.

11 Tan EM, Cohen AS, Fries JF, Masi AT, McShane DJ, Rothfield NF, et al. The 1982 revised criteria for the classification of systemic lupus erythematosus. Arthritis Rheum 1982;25:1271-7.

12 Hopkinson N, Doherty M, Powell R. The prevalence and incidence of systemic lupus erythematosus, UK, 1989-90. Br J Rheumatol 1993;32:110-15.

13 Census. County report. Part 2. London: HMSO, 1982

14 Disadvantages in Nottinghamshire. County Deprived Area Study 1983. Part 1. Nottingham: Nottinghamshire County Council, 1984

15 Epidemiological Graphics, Estimation and Testing (EGRET) statistics package. Cambridge, MA: Statistics and Epidemiology Research Corporation and Cytel Software Corporation, 1985-1991.

16 Christensen E. Multivariate survival analysis using Cox's regression model. Hepatology 1987;7:1346-58.
17 Estes D, Christian CL. The natural history of systemic lupus erythematosus by prospective analysis. Medicine $1971 \cdot 50: 85-95$

18 Hochberg MC, Boyd RE, Ahearn JM. Systemic lupus erythematosus: A review of clinical laboratory features and genetic markers in 150 patients with emphasis on demographic subsets. Medicine 1985;64:285-95

19 Clynes R, Dumitru C, Ravetch JV. Uncoupling of immune complex formation and kidney damage in autoimmune glomerulonephritis. Science 1998;279:1052-4.

20 Studenski S, Allen N, Caldwell D, Rice J, Polisson R. Survival in systemic lupus erythematosus. A multivariate analysis of demographic factors. Arthritis Rheum 1987;30: $1326-32$.

21 Ward M, Studenski S. Clinical manifestations of systemic lupus erythematosus. Identification of racial and socioeconomic factors. Arch Intern Med 1990;150:849-53.

22 D'Cruz D, Taub N, Gianotta L, McAlindon T, Hughes G. Anti-Sm antibodies: a potential risk factor for lupus Anti-Sm antibodies: a potential risk factor
nephritis. [Abstract]. Br J Rheumatol 1995;34:9.

23 Hopkinson N. Systemic lupus erythematosus: a clinical and epidemiological study. (Thesis DM). Nottingham, 1993.

24 Winfield J, Faiferman I, Koffler D Avidity of anti-DNA Winfield J, Faiferman I, Koffler D. Avidity of anti-DNA
antibodies in serum and IgG glomerular eluates from antibodies in serum and IgG glomerular eluates from patients with systemic lupus erythematosus. Association of
high avidity antinative DNA antibody with glomerulonephritis. J Clin Invest 1977;59:90-6.

25 Hay E, Croft P. Predicting outcome in current clinic attenders: a biased view. Ann Rheum Dis 1994;53: 357-8. 